Research review paper

\title{
Different isoforms of starch-synthesizing enzymes controlling amylose and amylopectin content in rice (Oryza sativa L.)
}

\author{
Manish K. Pandey a,b,*, N. Shobha Rani a , M. Sheshu Madhav a , R.M. Sundaram a , G.S. Varaprasad ${ }^{\text {a }}$ \\ A.K.P. Sivaranjani ${ }^{\text {a }}$, Abhishek Bohra ${ }^{\text {b }}$, G. Ram Kumar ${ }^{\text {a }}$, Anirudh Kumar ${ }^{\text {a }}$ \\ a Crop Improvement Section, Directorate of Rice Research (DRR), Rajendranagar, Hyderabad 500030, India \\ ${ }^{\mathrm{b}}$ Department of Genetics, Osmania University, Hyderabad 500007, India
}

\section{A R T I C L E I N F O}

Available online 31 August 2012

\section{Keywords:}

Starch-synthesizing enzymes

Starch synthases

Starch branching enzyme

Starch debranching enzyme

AGPase

Amylose content

Gelatinization temperature

\begin{abstract}
A B S T R A C T
Starch, composed of amylose and amylopectin, greatly influences rice cooking and textural quality, which in turn is controlled by various isoforms of several enzymes. Activity of one or more isoforms of starch-synthesizing enzymes results in various forms of starch structure based on the amylopectin chain length and average external, internal and core chain length distribution and hence results in varying physicochemical and cooking quality. Since the synthesis of starch is highly complex, it is crucial but essential to understand its biosynthetic pathway, starch structure and effects on the physicochemical properties that control eating and cooking quality, and alongside conduct research on gene/QTL mapping for use in marker-assisted selection (MAS) with a view to improve and select cultivars with most desirable range and class of rice starch properties. This article presents the updates on current understanding of the coordination among various enzymes/isoforms towards rice starch synthesis in endosperm and their effect on rice grain physicochemical, cooking and eating qualities. The efforts in identifying regions responsible for these enzymes by mapping the gene/QTLs have provided a glimpse on their association with physicochemical and cooking properties of rice and, hence, improvement is possible by modifying the allelic pattern, resulting in down or nil regulation of a particular enzyme. The clear understanding of the tissue specific coordination between enzyme isoforms and their subsequent effect in controlling eating and cooking properties will enhance the chances to manipulate them for getting desired range of amylose content (AC) and gelatinization temperature (GT) in improved cultivars through combining desired alleles through MAS
\end{abstract}

(C) 2012 Elsevier Inc. All rights reserved.

\section{Contents}

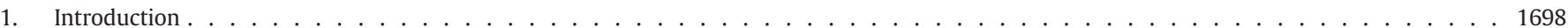

2. Starch-synthesizing enzymes and their isoforms in rice . . . . . . . . . . . . . . . . . . . . . . . . 1699

3. Physicochemical traits affecting rice grain quality . . . . . . . . . . . . . . . . . . . . . . . . . . . . 1699

3.1. Amylose content $(\mathrm{AC}) \ldots \ldots \ldots \ldots \ldots \ldots$

3.1.1. Genetics and mapping of quantitative trait loci (QTLs) for AC . . . . . . . . . . . . . . . . . . 1700

3.1.2. Identification of allele-specific markers . . . . . . . . . . . . . . . . . . . . . . . . 1701

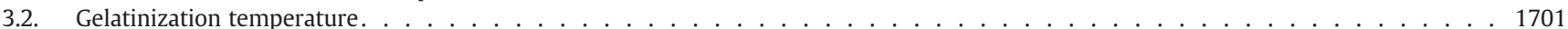

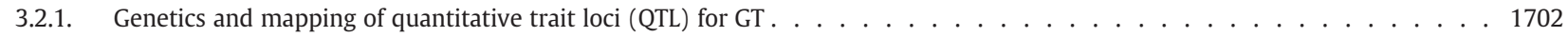

3.2.2. Role of amylopectin structure in controlling the GT . . . . . . . . . . . . . . . . . . . . . . . . . . . . . . 1702

3.2.3. Identification of allele-specific markers . . . . . . . . . . . . . . . . . . . . . . . . . . . . . . . . . . . .

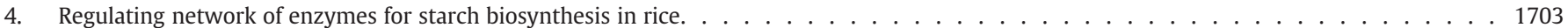

4.1. Adenosine diphosphate glucose pyrophosphorylase (AGPase) . . . . . . . . . . . . . . . . . . . . . . . 1703

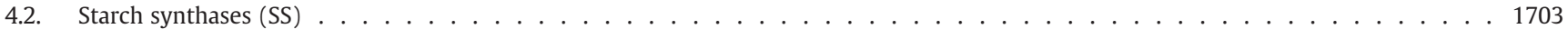

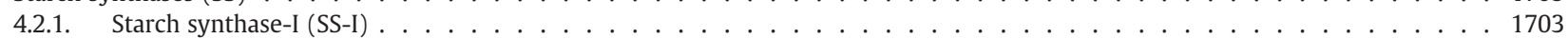

4.2.2. Starch synthase-II $(\mathrm{SS}-\mathrm{II}) \ldots \ldots \ldots \ldots \ldots$

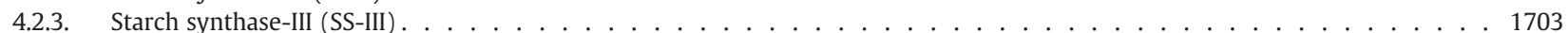

4.2.4. Starch synthase-IV (SS-IV) . . . . . . . . . . . . . . . . . . . . . . . . . . . . . . . . . . . . . . 1704

4.2.5. Granule bound starch synthase (GBSS) . . . . . . . . . . . . . . . . . . . . . . . . . . . . . 1704

\footnotetext{
* Corresponding author at: Applied Genomics Laboratory, International Crops Research Institute for the Semi-Arid Tropics (ICRISAT), Patancheru 502324, India and Department of Plant Pathology, University of Georgia (UGA)/USDA-ARS, Tifton, GA 31793, USA.
}

E-mail addresses: m.pandey@cgiar.org, m.pandey@uga.edu (M.K. Pandey). 
4.3. Starch branching enzymes $(\mathrm{SBE}) \ldots \ldots \ldots \ldots \ldots$

4.4. Starch debranching enzymes $(\mathrm{DBE}) \ldots \ldots \ldots \ldots$

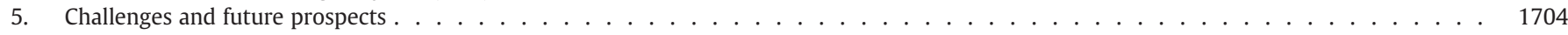

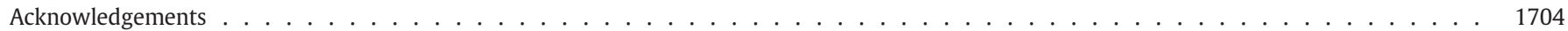

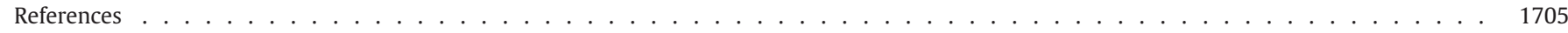

\section{Introduction}

Starch, an end product of photosynthesis in source tissues, is stored as energy reserves in the sink tissues and is composed of two major components, i.e., amylose and amylopectin. Earlier studies established strong association of starch structure with physical behavior and functionality (Fujita et al., 2003; Nakamura et al., 2002; Preiss and Sivak, 1996; Tetlow et al., 2004; Zhang et al., 2011). The variations in starch structure arise due to differential expression of various isoforms of starch biosynthetic enzymes. The varietal differences in the amylopectin structure exist predominantly due to chain length variation and play a critical role in determining physicochemical properties of starch in rice endosperm. Amylose content (AC) and gelatinization temperature (GT) are the two main measures to assess the rice grain quality. AC determines the firmness and sticky nature of cooked rice while rice with high GT requires higher temperature, more water and time to cook than those with low or intermediate GT. As the GT is directly correlated to the time required to cook rice, therefore, rices with intermediate GT are preferred over those with high or low-GT. These two properties have highest effect on cooked rice grain quality and thus play major role in influencing consumer's preference. In several studies, both AC and GT were found highly associated with eating and cooking properties of rice (Juliano et al., 1964; Kaw and Cruz, 1990; Shobha Rani et al., 2011a; Tang et al., 1989) and hence are important traits to consider together for improving rice grain quality of high yielding rice varieties worldwide to meet consumer's preference. Rice with good grain quality fetches higher returns to the farmers beside high demand due to increasing population/consumers (Shobha Rani et al., 2006). Therefore, it is imperative to improve AC and GT in desirable range into conventionally bred varieties as well as in the hybrids for their better acceptance by farmers, traders and consumers.

Recent studies have improved current understandings about regulating network of several isoforms of various enzymes for starch biosynthesis in higher plants. The structural variation, which contributes greatly to the physicochemical properties, is thought to be caused by the differences in the composition and relative activities of the isozymes of starch synthase (SS), starch branching enzyme (SBE) and debranching enzymes (DBE). Although few efforts were made to highlight the importance of rice grain quality and their possible improvement to meet consumer's preference (Shobha Rani et al., 2006), regulation of starch synthesis metabolism in higher plants and role/genetics of different enzymes in starch biosynthesis (James et al., 2003; Jeon et al., 2010; Keeling and Myres, 2010; Tetlow et al., 2004; Tian et al., 2010; Vandeputte and Decour, 2004) and identification/mapping of gene(s)/QTLs for AC and GT in rice (Shobha Rani et al., 2008), none of these studies emphasized to understand the association of different isoforms of starch-synthesizing enzymes with rice grain quality traits either directly or indirectly. However, the present article addresses the recent developments in biochemistry, genetics and genomics in relation to various enzymes controlling starch synthesis and their effect on the physicochemical and cooking properties of rice. We review recent speedy developments in all these individual areas which improved our existing understanding on enzyme coordination for starch synthesis, genes involved and identification of genomic regions responsible for grain quality traits. Finally, we suggest for a multidisciplinary holistic approach to get desirable range of physicochemical and cooking properties in rice cultivars through manipulating enzyme specific genes.

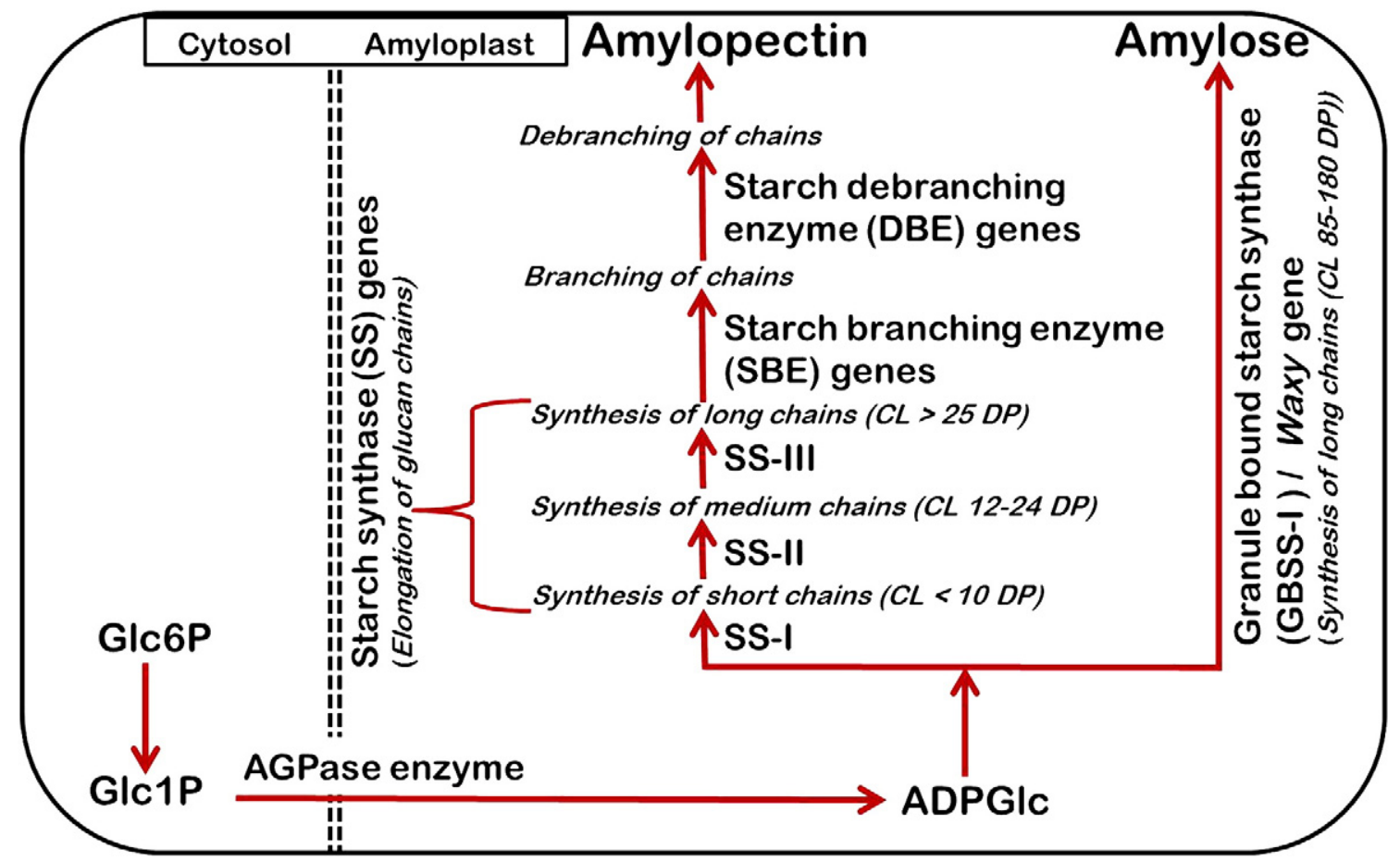

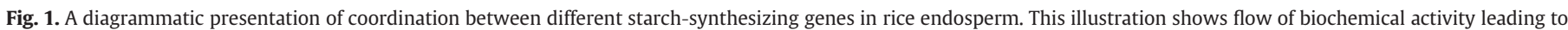
synthesis of amylose and amylopectin along with role of different starch-synthesizing genes at each step. 


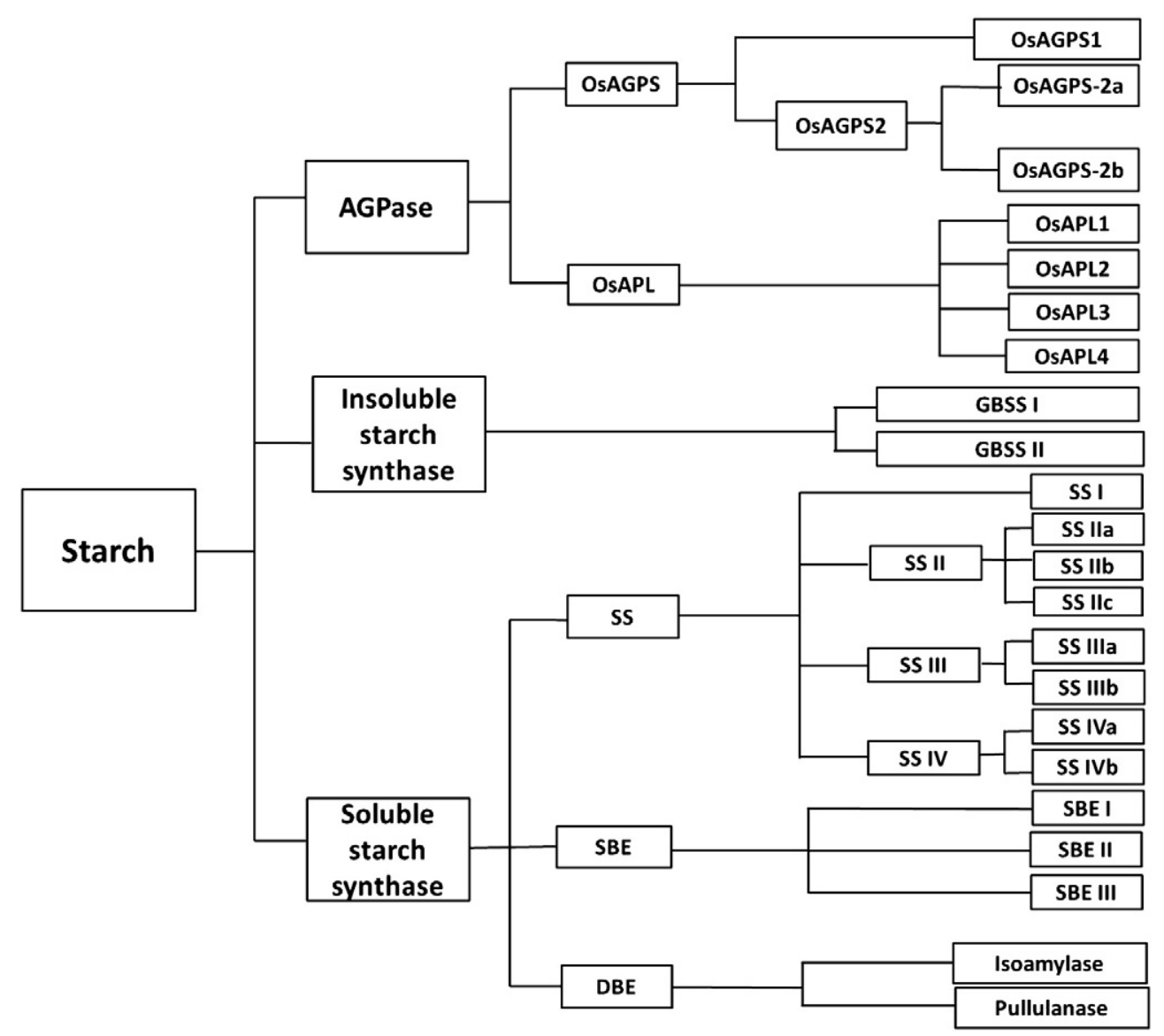

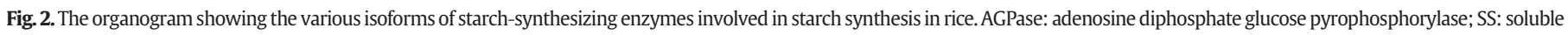
starch synthase; SBE: starch branching enzyme; DBE: debranching enzyme.

\section{Starch-synthesizing enzymes and their isoforms in rice}

Starch biosynthesis in higher plants including rice is catalyzed by four classes of enzymes, namely, ADP-Glc pyrophosphorylase (AGPase), starch synthase (SS), starch branching enzymes (SBE) and starch debranching enzymes (DBE). Of these, granule bound starch synthaseI (GBSS-I) (insoluble starch synthase) enzyme controls the synthesis of amylose in rice endosperm, while the soluble starch synthase (SS), SBE and DBE together control synthesis of amylopectin (Bao et al., 2002; Myers et al., 2000; Nakamura, 2002; Smith et al., 1974; Tanaka et al., 2004; Tetlow et al., 2004; Zhang et al., 2011) (Fig. 1). Several studies lead to identification of various SS isoforms through gene sequencing in several plant genomes. In rice, there are 10 SS isoforms which can be grouped into five types, namely, GBSS (I, II), SSI, SSII (SSIla, SSIIb and SSIIc), SSIII (SSIIIa and SSIIIb) and SSIV (SSIVa and SSIVb) isoforms (Hirose and Terao, 2004; Tetlow et al., 2004; Zhang et al., 2011) (Fig. 2). All these isoforms of starch-synthesizing enzymes coordinate together and form a regulating network to control starch synthesis in rice endosperm which affects grain cooking and eating quality (James et al., 2003; Jeon et al., 2010; Tian et al., 2010). Hence, the challenge lies in understanding the genetic basis and identification of genomic regions controlling these isoforms in order to develop cultivars with desirable combination of alleles controlling these isoforms.

\section{Physicochemical traits affecting rice grain quality}

Rice grain quality is mainly defined by four constituents, namely, milling, appearance, cooking and nutritional quality. Of these four constituents, traders are more interested in first two while consumers are more concerned for later two constituents. Furthermore, the consumer preferences for grain quality vary in each region across the world based on their food habits. Because of this reason, improvement in rice grain cooking quality has become most important research component in almost all the rice improvement programmes worldwide. Traits such as amylose content (AC) and gelatinization temperature (GT) which exert major effect on the eating and cooking qualities are itself controlled by physicochemical properties of starch in endosperm of rice grains.

Table 1

Inheritance of the starch properties traits in the rice.

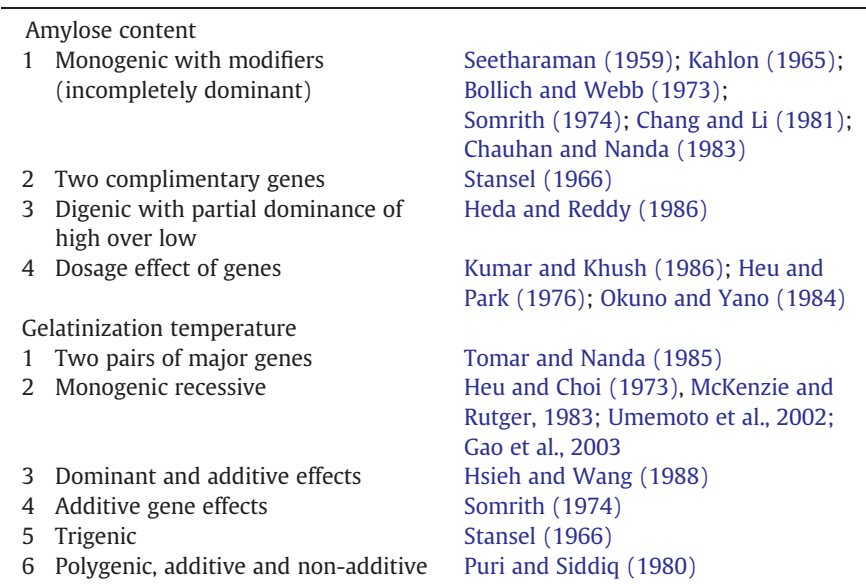


Table 2

Reported QTLs for the starch property traits in the rice.

\begin{tabular}{|c|c|c|c|c|c|}
\hline S. no. & Locus & Chrom. & Marker interval/marker & PVE (\%) & References \\
\hline \multicolumn{6}{|c|}{ Amylose content } \\
\hline \multirow[t]{2}{*}{1.} & $W x$ & 6 & Wx & 91.1 & He et al., 1999 \\
\hline & $q A C 5$ & 5 & RG 573-C624 & 11.8 & \\
\hline \multirow[t]{4}{*}{2.} & - & 6 & Waxy-RM 204 & 58.69 & Lanceras et al., 2000 \\
\hline & - & 4 & G177A-GA7-2 & 15.99 & \\
\hline & - & 3 & RM81-C158 & 11.28 & \\
\hline & - & 7 & OSR22-RM 10 & 9.18 & \\
\hline \multirow[t]{4}{*}{3.} & $q A C-6$ & 6 & R 2869-R 1962 & 80.7 & Li et al., 2003 \\
\hline & $q A C-5$ & 4 & C $1100-R 1783$ & 2.35 & \\
\hline & $q A C-4$ & 5 & C 624- C 128 & 1.45 & \\
\hline & $q A C-3$ & 3 & R 1927-R 3226 & 1.6 & \\
\hline 4. & $w x$ & 6 & RM 170 & 28.2 & Septiningsih et al., 2003 \\
\hline \multirow[t]{3}{*}{5.} & amy 6 & 6 & RM190-RM253 & 73.3 & Aluko et al., 2004 \\
\hline & amy 3 & 3 & RM 7RM 251 & - & \\
\hline & amy 8 & 8 & RM230-RM264 & - & \\
\hline \multirow[t]{3}{*}{6.} & $q A C-8$ & 8 & G1149-R727 & 16.5 & Wan et al., 2004 \\
\hline & $q A C-9 B$ & 9 & C609-C506 & 12.3 & \\
\hline & $q A C-12$ & 12 & XNpb189-2-XNpb24-2 & 14.7 & \\
\hline 7. & $q A C-6$ & 6 & RM190-RM510 & 61.8 & Tian et al., 2005 \\
\hline \multirow[t]{2}{*}{8.} & $q A C-2$ & 2 & R1843-G132 & 5.83 & Sun et al., 2006 \\
\hline & $q A C-6$ & 6 & S1084-R1952 & 74.67 & \\
\hline 9. & amy6-1 & 6 & RM3-RM217 & 39.6 & Amaravathi et al., 2008 \\
\hline \multirow[t]{3}{*}{10.} & - & 2 & RM183-RM573 & 1.1 & Wang et al., 2007 \\
\hline & - & 6 & RM586-MX21 & 88 & \\
\hline & - & 9 & RM296-RM105 & 1.2 & \\
\hline \multirow[t]{4}{*}{11.} & $q A C-1-1$ & 1 & R753-G359 & - & Zheng et al., 2008 \\
\hline & $q A C-1-2$ & 1 & C904-R2632 & - & \\
\hline & $q A C-4-3$ & 4 & C56-C820 & - & \\
\hline & $q A C-6-4$ & 6 & c952-waxy & 55.8 & \\
\hline 12. & $q A C-6$ & 6 & RM204-RM276 & 9.0 & $\begin{array}{l}\text { Shobha Rani et al., } \\
\text { 2011b }\end{array}$ \\
\hline \multicolumn{6}{|c|}{ Gelatinization temperature (GT) } \\
\hline \multirow[t]{2}{*}{1.} & alk & 6 & СТ506-C235 & 82.4 & He et al., 1999 \\
\hline & qASS-6 & 6 & CT201-RZ450 & 24.6 & \\
\hline \multirow[t]{3}{*}{2.} & - & 6 & C1478-RZ667 & 60.3 & Lanceras et al., 2000 \\
\hline & - & 2 & RG73-RM6 & 12.2 & \\
\hline & - & 6 & RM3-RM238 & 8.57 & \\
\hline \multirow[t]{4}{*}{3.} & qASS-6a & 6 & G200-C1478 & 69.44 & Li et al., 2003 \\
\hline & $q A S S-6 b$ & 6 & R2869-R1962 & 8.1 & \\
\hline & qASS-3 & 3 & C25-C515 & 2.32 & \\
\hline & alk & 6 & RM50-RM527 & - & Gao et al., 2003 \\
\hline \multirow[t]{2}{*}{4.} & alk6-1 & 6 & RM190-RM253 & 50.1 & Aluko et al., 2004 \\
\hline & alk6-2 & 6 & RM253-RM162 & 44 & \\
\hline \multirow[t]{2}{*}{5.} & $q G T-1$ & 1 & C955-C970 & 13.8 & Wan et al., 2004 \\
\hline & $q G T-3$ & 3 & C1677-R3156 & 20.9 & \\
\hline \multirow[t]{2}{*}{6.} & $q G T-6$ & 6 & RM276-RM121 & 80.3 & Tian et al., 2005 \\
\hline & qGT 3-1 & 3 & R2856-R3226 & 8.31 & Sun et al., 2006 \\
\hline \multirow[t]{2}{*}{7.} & $q G T-6$ & 6 & G200-R2171 & 64.42 & \\
\hline & asv6-1 & 6 & RM3-RM217 & 6.9 & Amaravathi et al., 2008 \\
\hline 8. & qGC-3 & 3 & R2856-R3226 & 12.74 & \\
\hline \multirow[t]{2}{*}{9.} & - & 6 & MX21-RM204 & 7.7 & Wang et al., 2007 \\
\hline & - & 6 & RM276-RM549 & 87.8 & \\
\hline 10. & qASV-6-1 & 6 & Waxy-C1496 & 11.3 & Zheng et al., 2008 \\
\hline 11. & qGT-2 & 2 & RG256-RZ213 & 14.41 & Govindraj et al., 2009 \\
\hline & qGT-5 & 5 & RZ70-RZ225 & 15.39 & \\
\hline 12. & $q G T-6$ & 6 & RM276-RM217 & 30.7 & Shobha Rani et al., 2011b \\
\hline
\end{tabular}

\subsection{Amylose content $(A C)$}

Starch has two major components, namely, linear $\alpha$-polyglucan amylose and branched $\alpha$-polyglucan amylopectin. In general, stored starch in the higher plants is composed of $20-30 \%$ amylose and $70-$ $80 \%$ amylopectin. Rice varieties can be classified based on varied range of AC such as waxy (0-2\%), very low (3-12\%), low (13-20\%), intermediate (21-25\%) and high ( $\geq 26 \%$ ) (Juliano et al., 1981). Rice grains with high AC $(\geq 26 \%)$ cook dry, become less tender and hard upon cooling while rice grains with low AC $(<20 \%)$ cook moist and become very sticky. That is why rice with intermediate AC (20-25\%) is preferred in majority of the rice-growing/consuming regions of the world, except in few regions where only low-AC japonicas are preferred. Therefore, the efforts need to be intensified in developing perfect markers for differentiating each class of AC and marker- assisted introgression of desired allele, which will help the breeders in developing varieties with preferred $\mathrm{AC}$ range as per local and international consumer preference for rice cooking quality.

\subsubsection{Genetics and mapping of quantitative trait loci (QTLS) for AC}

Several studies on the genetics of AC had reported involvement of one major gene and several modifiers with high AC incompletely dominant over low AC (Chang and Li, 1981; Chauhan and Nanda, 1983; Somrith, 1974) (Table 1). However, in addition to the waxy gene which controls AC, the involvements of two complimentary genes were also reported (Stansel, 1966). Furthermore, the differences in AC were observed due to the dosage of amylose genes in the endosperm (Kumar and Khush, 1986), but the AC was not directly proportional to the number of $W_{x}$ dose (Heu and Park, 1976; Okuno, 1978). There are several reports on the association of these markers 
Table 3

The primer sequences of the SSR, CAPS, STS and SNP markers identified for the starch-synthesizing genes in rice.

\begin{tabular}{|c|c|c|c|c|}
\hline Genes & Type of marker & Forward primer $\left(5-3^{\prime}\right)$ & Reverse primer $\left(5-3^{\prime}\right)$ & References \\
\hline \multirow[t]{2}{*}{$W x$} & SSR & CTTTGTCTATCTCAAGACAC & TTGCAGATGTTCTTCCTGATG & Ayres et al., 1997 \\
\hline & CAPS, ACC1 & TTTCCAGCCCAACACCTTAC & TTGCAGATGTTCTTCCTGAT & \\
\hline \multirow[t]{2}{*}{ Sss 1} & SSR & GATCCGTTTTTGCTGTGCCC & СCTCCTCTCCGCCGATCCTG & $\begin{array}{l}\text { Bao et al., 2002; } \\
\text { Larkin and Park, } 2003\end{array}$ \\
\hline & STS & TCTAGATTGCTACACGTGAGAGG & TCTCCACGATAACTTCCACC & Ayres et al., 1997 \\
\hline \multirow[t]{4}{*}{ Sss11a (alk) } & STS & TCTAGATTGCTACACGTGAGAGG & GGAGCCACCTGTAAAGCGTG & \\
\hline & SNP (1) & CTGGATCACTTCAAGCTGTACGAC & GCCGGCCGTGCAGATCTTAAC & Bao et al., 2006 \\
\hline & SNP (2) & CAAGGAGAGCTGGAGGGGGC & ACATGCCGCGCACCTGGAAA & \\
\hline & SSR & CTTTGATAGTTCGAATGGTT & CAATGTTTCTCCGTGATGAT & Gao et al., 2003 \\
\hline \multirow[t]{4}{*}{ Sbe I } & SSR & ATTTCTTTGGCCACAGGCGA & CCCAGATTCGGAACAAGAAC & Akagi et al., 1996 \\
\hline & STS & GAGTTGAGTTGCGTCAGATC & AATGAGGTTGCTTGCTGCTG & Han et al., 2004 \\
\hline & CAPS,ACC11 & CCGAGGGAATGCCAGGAGTACCAG & GAACCACAACCAAGTCCAAGGCAA & Liu et al., 2006 \\
\hline & STS & GAGTTGAGTTGCGTCAGATC & CAGCAGCAAGCAACCTCATT & \\
\hline \multirow[t]{2}{*}{ Sbe III } & CAPS, Spe 1 & GTCTTGGACTCAGATGCTGGACTC & ATGTATAACTGGCAGTTCGAACGG & \\
\hline & STS & TCGGTCAATTCGGTTAGTCTCCTC & ACATCCTCTAGCATACTGGCGACTC & \\
\hline \multirow{2}{*}{ Pul } & STS & GGGTTCGCTTTCACAACACAG & GTCACGACATAAGAGAAGCTGC & Ayres et al., 1997 \\
\hline & STS & AGTTCGCTAGTCATCTGCTCG & CCACATGTCCTTGTCTCCACTT & \\
\hline \multirow[t]{2}{*}{ Isa } & CAPS, Ssp 1 & CTTGTGTCTGGTGAGGCTTCTA & CCTAGTGACTGGACTCATGGTT & \\
\hline & STS & CCTGTCTTGCACGTGCGGTA & GCACGGTTCTGATGTACGAGAG & \\
\hline
\end{tabular}

with different quality characteristics in the rice germplasm. Among these, two SNPs in the exons of $W x$ gene that resulted in amino acid substitutions were found to be associated with AC and viscosity characteristics (Larkin and Park, 2003). However, with indel markers for SBE1, SBE3 and DBE genes, no association could be established between the marker alleles and the variation in apparent amylose content (AAC) and paste viscosity characteristics in a segregating population. More significantly, efforts made in the mapping of QTLs yielded in identification of one major QTL on chromosome 6 with high phenotypic variation along with several small effect QTLs distributed on other regions of the rice genome (He et al., 1999; Lanceras et al., 2000; Lee et al., 2007; Gao et al., 2003; Septiningsih et al., 2003; Aluko et al., 2004; Wan et al., 2004; Tian et al., 2005; Sun et al., 2006; Amaravathi et al., 2008; Wang et al., 2007; Zheng et al., 2008; Govindraj et al., 2009; Shobha Rani et al., 2011b) (Table 2). Association study with above identified flanking markers revealed that these molecular markers can differentiate low-AC genotypes from the high and intermediate AC genotypes; however, none of the identified linked markers can differentiate genotypes with intermediate and high AC.

\subsubsection{Identification of allele-specific markers}

Amylose is a linear polymer of $\alpha$-(1-4) linked D-glucopyranosyl units with few $\alpha-(1-6)$ linkages and has average degree of polymerization (DPn) of 800-4920, average chain length (CL) of 250-670 and $\beta$-amylolysis limits of 73-95\% (Morrison and Karkalas, 1990). It is controlled by waxy gene encoding granule bound starch synthase-I (GBSS-
I). The simple sequence repeat (SSR) polymorphism with respect to $(\mathrm{CT})_{\mathrm{n}}$ repeats was also correlated (Bligh et al., 1995; Tan and Zhang, 2001) for waxy, low, intermediate and high AC with (CT) ${ }_{17},(\mathrm{CT})_{18-19}$, $(\mathrm{CT})_{11-10}$ and $(\mathrm{CT})_{11-10}$, respectively. Few studies (Isshiki et al., 2000; Chen et al., 2008; Mikami et al., 2008) confirmed the existence of five alleles at waxy locus, i.e., waxy, $W x^{a}, W x^{i n}, W x^{b}$ and $W x^{o p}$. A single nucleotide polymorphism (SNP) in intron 1 differentiates low amylose $\left(W x^{a}\right)$ from the high $\left(W x^{b}\right)$ and intermediate $\left(W x^{i n}\right)$ classes. Further, a SNP at exon 6 (which changes serine to tyrosine) can differentiate intermediate AC from the high AC while SNP at exon 4 (which changes aspartate to glycine) shows low GBSS activity and gives opaque $\left(W x^{o p}\right)$ phenotype. As the SNP genotyping facility is not available in majority of the breeding institutes, allele/SNP specific PCR-based markers may be developed to differentiate various AC classes and should be integrated with conventional breeding programme for grain quality improvement. It is also estimated that the $W x$ locus alone may not explain all the observed AC variation among rice cultivars and, hence, some minor genes might also be involved. Nevertheless, until availability of robust and perfect markers for each AC class, Waxy SSR, CT-SSRs together with G-T SNP may be used by rice breeders to develop rice varieties with desirable range of AC (Table 3).

\subsection{Gelatinization temperature}

Gelatinization temperature (GT) is a physical property of the rice starch and refers to the range of temperature within which starch

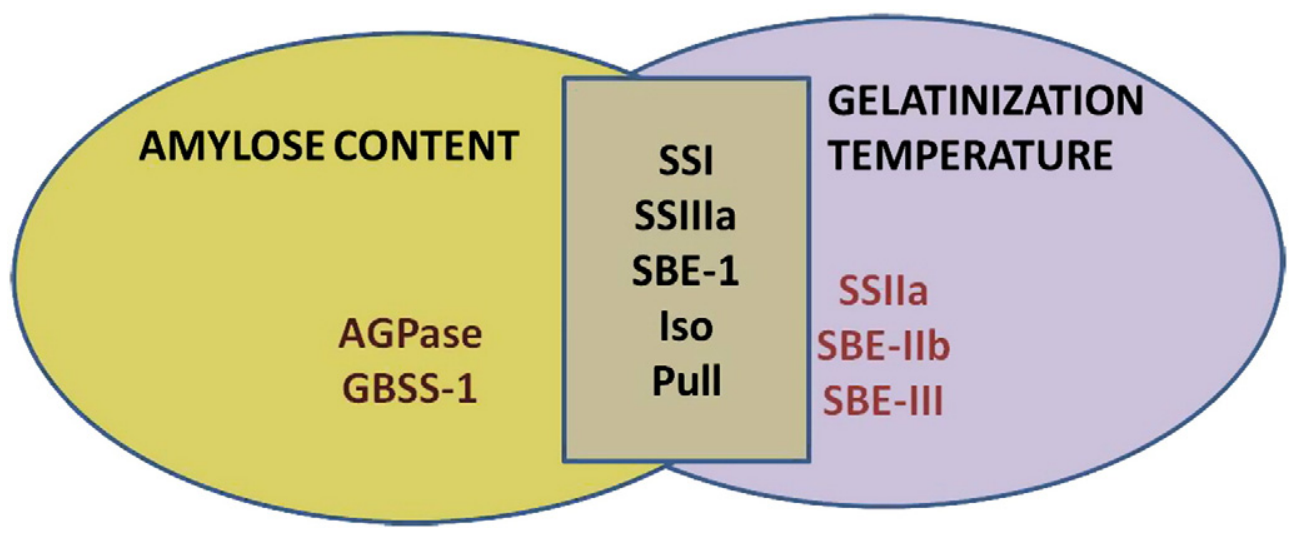

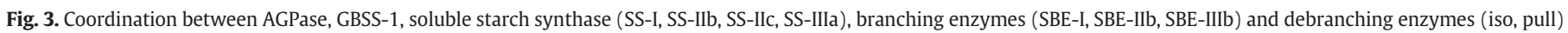
in synthesizing starch in rice endosperm, controlling the two key rice grain quality traits, i.e., amylose content and gelatinization temperature. 
Table 4

Enzymes playing key roles in the starch biosynthesis in the rice.

\begin{tabular}{|c|c|c|}
\hline Enzymes & Role in starch biosynthesis & Reference \\
\hline \multicolumn{3}{|c|}{ ADP-glucose pyrophosphorylase } \\
\hline ADPglc PP & Transport of ADP-glucose & Asaoka et al., 1993 \\
\hline OsAPS-1 & Starch biosynthesis in seed & \\
\hline OsAPS-2a & Starch biosynthesis in leaves & Lee et al., 2007 \\
\hline OsAPS-2b & Starch biosynthesis in seed & \\
\hline OsAPL-1, 3,4 & Starch biosynthesis in plastid & \\
\hline OsAPL-2 & Starch biosynthesis in seed & \\
\hline \multicolumn{3}{|c|}{ Granule bound starch synthase enzyme (GBSS) } \\
\hline GBSS-I & $\begin{array}{l}\text { Encoded by the Waxy locus facilitating amylosyntheses in storage tissues through } \\
\text { formation of long chains. It was also found responsible for extension of long glucans within } \\
\text { the amylopectin fraction. } \\
\text { Extension of long glucan chains within amylopectin fractions }\end{array}$ & $\begin{array}{l}\text { Sano, 1984; Yano et al., 1988; Asaoka et al., 1993; } \\
\text { Mikami et al., 1999; } \\
\text { Tetlow et al., 2004 } \\
\text { Delrue et al., 1992; Maddelein et al., 1994; } \\
\text { van de Wal et al., } 1998\end{array}$ \\
\hline GBSS-II & Amylose synthesis in leaves and other non-storage tissue of plants & $\begin{array}{l}\text { Nakamura, 2002; Fujita and Taira, 1998; Vrinten and } \\
\text { Nakamura, } 2002\end{array}$ \\
\hline \multicolumn{3}{|c|}{ Starch synthases (SS) } \\
\hline SS-I & $\begin{array}{l}\text { Synthesis of short chains of DP 8-12 from very short DP 6-7 chains emerging from the branch } \\
\text { point in the A or B (1) chain of amylopectin. Functions from the very early to the very late stage } \\
\text { of endosperm development. }\end{array}$ & $\begin{array}{l}\text { Nakamura, 2002; Umemoto et al., 2002; Fujita et al., 2006; } \\
\text { Nakamura, 2002; Umemoto et al., 2002; Nakamura et al., 2005; } \\
\text { Zhang et al., } 2011\end{array}$ \\
\hline SS-IIa & $\begin{array}{l}\text { Synthesis of medium size chains (DP 12-24) by elongating A and B1 chains of amylopectin. Its } \\
\text { activity determines type (indica or japonica) of amylopectin structure in rice endosperm. }\end{array}$ & \\
\hline SS-IIb & $\begin{array}{l}\text { Barely expressed in the seed and only active earliest period of grain formation. Mostly } \\
\text { expressed in leaves. }\end{array}$ & Ohdan et al., 2005 \\
\hline SS-IIc & Immerged much before SS-IIa \& b and is expressed mostly in endosperm along with SS-Ila. & Ohdan et al., 2005 \\
\hline SS-IIIa & Formation of long B1 and B2 chains of amylopectin in endosperm & $\begin{array}{l}\text { Nakamura, 2002; Ohdan et al., 2005; Fujita et al., 2007; } \\
\text { Zhang et al., } 2011\end{array}$ \\
\hline SS-IIIb & Mostly expressed in leaves and less in seed. & Ohdan et al., 2005 \\
\hline $\begin{array}{l}\text { SS-IIIc and SS-IVa } \\
\quad \& \text { SSIVb }\end{array}$ & Function unknown & \\
\hline \multicolumn{3}{|c|}{ Starch branching enzymes (SBE) } \\
\hline SBE-I & Synthesis of B1, B2, B3 chains of amylopectin & Nakamura, 2002; Satoh et al., 2003a, 2003b \\
\hline SBE-IIa & Starch synthesis in leaves and other non-storage tissue of plants & $\begin{array}{l}\text { Blauth et al., 2001; } \\
\text { Nakamura et al., } 2010\end{array}$ \\
\hline SBE-IIb & $\begin{array}{l}\text { Role in synthesis of A and B1 chains of amylopectin in storage tissues by transferring short } \\
\text { chains which are then extended by SS enzymes to form A and B1 chains of amylopectin }\end{array}$ & $\begin{array}{l}\text { Asaoka et al., 1993; Nishi et al., 2001; Tanaka et al., 2004; } \\
\text { Nakamura et al., 2010; Butardo et al., } 2011\end{array}$ \\
\hline SBE-III & Synthesis of 1-6 branching linkage & $\begin{array}{l}\text { Chen et al., 2004; } \\
\text { Nakamura et al., } 2010\end{array}$ \\
\hline \multicolumn{3}{|c|}{ Starch debranching enzymes (DBE) } \\
\hline $\begin{array}{l}\text { DBE (isoamylase } \\
\text { and } \\
\text { pullulanase) }\end{array}$ & Debranching amylopectin chains by hydrolyzing $\alpha$ (1-6) bonds & $\begin{array}{l}\text { Nakamura, 1996; Kubo et al., 1999; Fujita et al., 2003; } \\
\text { Wong et al., 2003; Utsumi et al., } 2011\end{array}$ \\
\hline
\end{tabular}

granules start swelling irreversibly in hot water. In other words, GT determines the time taken to cook the rice. The quality and quantity of starch in rice endosperm together with GT strongly influence the cooking quality of rice (Ghosh and Govindswamy, 1997) such as water uptake, volume expansion and linear kernel elongation (Tomar and Nanda, 1985). The rice varieties with intermediate GT are preferred and mostly the Indian basmati varieties have intermediate GT but these varieties are poor in yield.

\subsubsection{Genetics and mapping of quantitative trait loci (QTL) for GT}

Genetical studies could not conclude the inheritance pattern due to several contradictory reports such as dominant and additive (Hsieh and Wang, 1988), digenic (Stansel, 1966), and polygenic (Puri and Siddiq, 1980) mode of inheritance. However, several QTL mapping studies zeroed on existence of a major QTL on chromosome 6, explaining high phenotypic variation (Aluko et al., 2004; Amaravathi et al., 2008; Gao et al., 2003; Govindraj et al., 2009; He et al., 1999; Lanceras et al., 2000; Shobha Rani et al., 2011b; Sun et al., 2006; Tian et al., 2005; Wan et al., 2004; Wang et al., 2007; Zheng et al., 2008) (Table 2). These studies also pointed out the possible role of either alkali degeneration gene (alk) (Aluko et al., 2004; Bao et al., 2004; Fan et al., 2005; Gao et al., 2003; He et al., 1999) or waxy gene (Tan et al., 1999; Zheng et al., 2008) also in controlling GT. More interestingly, the starch synthase IIa (SSIIa) gene was found to be located at the alk locus on chromosome 6 in the rice genome (Umemoto et al., 2002). Map-based cloning of the alk locus revealed that this locus encodes SSIIa and nucleotide substitutions in the coding sequence of SSIIa reported to cause the alteration in GT (Gao et al., 2003).

\subsubsection{Role of amylopectin structure in controlling the GT}

The gelatinization behavior of starch granules in rice is predominantly determined by the amylopectin structure (Lanceras et al., 2000; Umemoto et al., 2002) and amylopectin consist of $\alpha$ (1-4) linked D-glucosyl chains and is highly branched with $\alpha(1-6)$ bonds (Bulean et al., 1998). Rice starch amylopectins have chain length (CL) of 19-23 (Takeda et al., 1987). Compared to amylopectins of Japonica (CL 19-20), Indica have higher CL of 21-22, while waxy Japonica rice starches have the lowest CL (17-19) (Morrison and Karkalas, 1990). Very short chains were found negatively correlated, while the longer chains were found positively correlated to GT (Nakamura et al., 2002; Noda et al., 2003; Vandeputte and Decour, 2004). The mechanism underlying the synthesis of amylopectin, which controls the GT, is highly complicated. Three classes of enzymes are involved in the synthesis of amylopectin and each class has multiple isoforms. Synthesis of amylopectin, a complex structure, arises due to subtle interplay between starch synthase (SS), starch branching enzyme (SBE) and the starch debranching enzyme (DBE). The function of the SS is to catalyze the chain-elongation reaction of $\alpha$-1-4-glucosidic linkage by transferring a glucose moiety from ADPglucose to the non reducing end of the linkage; the SBE introduces a $\alpha-1-6$-glucosidic linkage into a polyglucan and the DBE, which hydrolyzes an $\alpha-1-6$ glucosidic linkage of a-polyglucan (Myers et al., 2000; Nakamura, 2002). The above studies indicates clearly that group of SS enzymes (SS-I, SS-II, SS-III and SS-IV), SBE and DBE play important role 
in the amylopectin biosynthesis, structure and their distribution in different tissues (Figs. 1-3). These structural changes in the amylopectin increase/decrease the gelatinization temperature of endosperm starch.

\subsubsection{Identification of allele-specific markers}

Since various isoforms of several enzymes are involved in the synthesis of amylopectin, it is very complicated but necessary to understand the contribution of each isoform of all the enzymes in isolation and in combinations. The ultimate requirement is the development of isoform-specific molecular markers for possible improvement through MAS using allele-specific markers. To achieve this, molecular markers tagged to genes encoding two soluble SSs (SSSI and SSSIIa), two SBEs (SBEI and SBEIII), and two starch DBEs (isoamylase and pullulanase) enzymes have been identified and evaluated for the effects of these enzymes on the cooking quality (He et al., 2006) (Fig. 3). In parallel, Nakamura et al. (2005) analyzed the effects of amino acid replacement caused by these SNPs on the enzyme activity and on the amylopectin structure and GT, and the results indicated that two SNPs (at 4,198 and 4,229/4,330 bp) are essential for SSIIa activity and granule association. In addition, nucleotide diversity of SSIIa gene was studied to investigate the relationships between the SNPs identified in these rices and their GT values. This study confirmed role of GC/TT polymorphism in SSIIa in differentiating the rices with high- or intermediate-GT from those with low-GT with about $90 \%$ correct prediction (Bao et al., 2006). In another study, at least 3 different alleles for SSIIa gene were postulated, i.e., one in the Japonica rice and two in the Indica rice varieties. Furthermore, two alleles for either low- or high-GT for alk2(t) gene have also been reported. Thus, the rich diversity of the GT character in the rice probably resulted from the various combinations of these alleles. However, still further study is required to quantify the effects of individual as well effects of many enzymes in combination using functional genomics approach to move towards pyramiding of desired allele combinations.

\section{Regulating network of enzymes for starch biosynthesis in rice}

Starch biosynthesis in higher plants is catalyzed by four classes of enzymes, namely, ADP-Glc pyrophosphorylase (AGPase), SS, SBE and DBE (Myers et al., 2000; Nakamura, 2002; Smith et al., 1974; Tetlow et al., 2004; Zhang et al., 2011) (Figs. 1-3; Table 4). Recent advancements in the research have improved our understanding on the structure and functions of various isoforms of starch-synthesizing enzymes towards the synthesis of starch in rice endosperm and other nonstorage tissues. The detailed information on starch biosynthesis is out of purview of this article and, hence, only a brief role of enzyme isoforms is mentioned here along with efforts updates for identification of linked markers for these enzymes.

\subsection{Adenosine diphosphate glucose pyrophosphorylase (AGPase)}

ADP-Glc pyrophosphorylase (AGPase) consists of two large (AGP-L) and two small (AGP-S) catalytic subunits controlled by a minimum of six genes (Lee et al., 2007) (Fig. 2). Its major activity (65-95\%) is performed by its cystolic isoforms which facilitates import of ADPglc into amyloplasts in the developing endosperm of rice (Lee et al., 2007; Tetlow et al., 2004; Utsumi et al., 2011). In amyloplasts, ADPglc acts as soluble precursor and substrate for the starch synthesis. Study of rice AGP gene family in detail revealed involvement of a total of six genes responsible for AGPase enzyme which includes two genes encoding small subunits (OsAGPS-1 and OsAGPS-2 [ $\mathrm{a}$ and $\mathrm{b}]$ ) and four genes encoding large subunit (OSAPL-1, OSAPL-2, OsAPL-3 and OsAPL-4). The multiple genes showed strong tissue specificity in their expression such as the transcript of OsAGPS-2 was found leaf specific; OSAPL-1, OSAPL-3 and OSAPL-4 plastid specific; and the remaining three isoforms (OsAGPS-1, OsAGPS-2b and OsAPL-2) were found to be seed specific (Lee et al., 2007; Ohdan et al., 2005)
(Table 4). Analysis of OsAGPS-2 and OsAPL-2 mutants revealed that a lesion of one of the two cytosolic isoforms causes a shrunken endosperm due to remarkable reduction in the starch synthesis in rice endosperm. Although as per current understanding, this enzyme is responsible for transport of ADPglc into amyloplasts but still detailed study is required to enhance our current understanding on its production, activity and functionality.

\subsection{Starch synthases (SS)}

Ten isoforms of SS have been distinguished in rice which can be grouped into five classes i.e. SS-I, SS-II (a,b,c), SS-III (a,b), SS-IV (a,b) and granule bound SS (GBSS) (I,II) (Hirose and Terao, 2004; Nakamura, 2002; Tetlow et al., 2004; Zhang et al., 2011). These enzymes together perform a chain of reactions and catalyze the transfer of the glucosyl moiety of the soluble precursor ADPglc to the reducing end of a pre-existing $\alpha(1-4)$ linked glucan primer to synthesize the insoluble glucan polymers amylose and amylopectin (Tetlow et al., 2004).

\subsubsection{Starch synthase-I (SS-I)}

It plays an important role in the starch biosynthesis, has no isoforms and is involved in synthesis of short chains ( $\leq 10 \mathrm{DP})$. Abundance of short chains (SC) and shortage of long chains (LC) decrease the gelatinization temperature. Soluble starch synthases (SS-I, II, III, IV) have higher affinity for the ADPglc than the GBSS and is mainly responsible for amylopectin elongation. The N-terminal extension of SSI is important for its proper binding with the starch granules (Imparl-Radosevich et al., 2003). Amylopectin chains are synthesized by the coordinated actions of SSI, SSIIa and SSIIIa isoforms, and the activity of SSI is reported to be higher than that of the SSIIa and SSIIIa enzymes (Fujita et al., 2006).

\subsubsection{Starch synthase-II (SS-II)}

Three isoforms (SS-IIa, IIb, IIc) for SS-II enzyme have been identified in rice. The SS-IIb gene is mostly expressed in leaves while substantial expression of SS-IIa and SS-IIc genes has been observed in the endosperm (Hirose and Terao, 2004; Nakamura et al., 2005; Ohdan et al., 2005; Zhang et al., 2011). The interesting and important fact is that the SS-IIa gene, the alk ( $t$ ) gene (controlling alkali digestion), the gel $(t)$ gene (controlling difference in gelatinization) and the $a c l(t)$ gene (controlling variation in the amylopectin chain length distribution i.e. ratio of short $(\leq 11)$ /medium size (12-24) amylopectin chains) are mapped to the same locus on chromosome 6 in rice. The SS-IIa gene plays a specific role in the synthesis of the medium size glucon chains (12-24 DP) by elongating short chains ( $\leq 10 \mathrm{DP}$ ) (Table 4). Although SS-IIa gene is a minor contributor to the total SS enzyme activity in the endosperm as compared to SS-I and SS-III genes, loss/down regulation of SS-IIa gene has the major impact on quantity and composition of starch in rice endosperm (Yu et al., 2011).

\subsubsection{Starch synthase-III (SS-III)}

SS-III enzyme possesses two isoforms, i.e., SS-IIIa and SS-IIIb, in rice and is specifically expressed in the developing rice endosperm and leaf, respectively (Fujita et al., 2007; Hirose and Terao, 2004; Ohdan et al., 2005; Zhang et al., 2011). The deficiency in the SS-IIIa, the second major SS enzyme in the developing rice endosperm, affected the structure of amylopectin, amylose content and the physicochemical properties of the starch granules in two ways: directly by the SSIIIa enzyme deficiency itself, resulting in the chain length increase (DP 10-15 and DP 20-25), and indirectly by the enhancement of both the SS-I and GBSS-I gene transcripts (Fujita et al., 2007) (Table 4). It is also been suggested that the GT of the starch could be regulated by the ratio of $\leq 12-16 \mathrm{DP} />12-16 \mathrm{DP}$ in the $\mathrm{A}$ chains and the exterior part of B chains of amylopectin (Fujita et al., 2006). 
The decrease in short chains and increase in medium chains have been observed in the rice SS-IIIa mutants (Fujita et al., 2007).

\subsubsection{Starch synthase-IV (SS-IV)}

Two isoforms, i.e., SS-IVa and SS-IVb, have been identified for SS-IV enzyme. So far no mutant has been isolated with lesions in gene controlling SS-IV enzyme and, hence, no role could be assigned for this class of $\mathrm{SS}$ in the process of starch biosynthesis.

\subsubsection{Granule bound starch synthase (GBSS)}

GBSS enzyme comprises of two isoforms (GBSS-I, GBSS-II). The GBSS-I is encoded by waxy locus and is involved in the synthesis of long amylopectin (CL 85-180) chains (Cai et al., 1998; Denyer et al., 1996; Fu and Xue, 2010; Takeda et al., 1987; Wang et al., 1995) in higher proportion, resulting in the absence of very long chains in the waxy rices. The expression of GBSS-I enzyme appears to be confined mostly to the storage tissues, while GBSS-II enzyme is encoded by another separate gene and is responsible for the amylose synthesis in the leaves (Cai et al., 1998; Fu and Xue, 2010; Fujita and Taira, 1998; Vrinten and Nakamura, 2002). The huge variation in rice germplasm for AC is determined by the activity level of the GBSS-I, which in turn depends on the 5 alleles $\left(W x^{a}, W x^{b}, W x^{i n}, W x^{o p}\right.$ and $w x$ ) (Sano, 1984; Mikami et al., 2008; Chen et al., 2008). A microsatellite (SSR with 8-20 CT repeats) in the un-translated region of exon 1 of the GBSS-I gene discriminates between different types of amylose (Ayres et al., 1997). A relationship between AC and number of CT repeats was established through several studies (Ayres et al., 1997; Bao et al., 2002; Bergman et al., 2000; Bligh et al., 1995; Fitzgerald, 2004; Olsen and Purugganan, 2002) and been concluded as follow: (a) low amylose temperate Japonica rices possess $W x^{a}$ allele (18-19 CT), (b) medium amylose tropical japonica possess $W x^{\text {in }}$ allele (11-10 CT repeats), and (c) high amylose Indica rices carry $W x^{b}$ allele (14-20 CT repeats).

\subsection{Starch branching enzymes (SBE)}

After elongation of the glucal chains by the SS enzyme, the another enzyme, namely, SBE with two isoforms, i.e. SBE-I and SBE-II, generates $\alpha-(1-6)$ linkages by cleaving internal $\alpha-(1-4)$ bonds and transferring the released reducing ends to $\mathrm{C} 6$ hydroxyls to form the branched structure of the amylopectin molecule. SBE-II proteins transfer shorter chains and show a higher affinity towards amylopectin as compared to the SBE-I, which shows higher rates of branching with amylose (Guan and Preiss, 1993; Nakamura et al., 2010; Takeda et al., 1993; Tanaka et al., 2004; Tetlow, 2006; Tetlow et al., 2004) (Table 4). The termini (N- and C-) of these enzymes play important roles in determining the substrate preference, catalytic capacity and chain length transfer (Kuriki et al., 1997). In the monocots, the SBE-II gene has two closely related but distinct gene products i.e., SBE-IIa and SBE-IIb enzymes (Rahman et al., 2001). Down regulation or elimination of SBE-I gene activity showed minimal effects on the starch synthesis (Blauth et al., 2002; Flipse et al., 1996; Satoh et al., 2003b), while SBE-IIa gene showed clear/major role in the leaf starch synthesis and no effect on storage starch of endosperm (Blauth et al., 2001). The SBE-IIb enzyme has a distinct role in the transfer of short chains, which are then most probably extended by SS to form A and B1 chains of the rice amylopectin cluster structure (Nishi et al., 2001). Study on SBE-I mutants of rice have shown decreased level of the amylopectin chains with DP 12-20 and DP $\geq 37$, and increased level of amylopectin chains with DP 24-34 (Satoh et al., 2003a, 2003b). Hence, the role of the SBE-I enzyme is clear and important in the synthesis of B1, B2 and B3 amylopectin chains (Nakamura, 2002; Satoh et al., 2003a, 2003b). One more enzyme isoform (SBEIII) has also been reported recently (Chen et al., 2004), which plays an important role in the synthesis of 1-6 branching linkage.

\subsection{Starch debranching enzymes (DBE)}

The DBE catalyses the hydrolysis (debranch) of $\alpha-(1-6)$ bonds in amylopectin and removal of the improper branch. Two types of DBEs have been distinguished based on their substrate specificity, namely, isoamylase and pullulanase. Isoamylase debranches glycogen, phytoglycogen and amylopectin, but does not attack pullulan, while pullulanase attacks both pullulan and amylopectin, but does not attack glycogen and phytoglycogen (Nakamura, 1996; Utsumi et al., 2011) (Table 4). Although specific roles of isoamylase and pullulanase are not yet clear, the sugary-I and isoamylase-I mutants of the rice endosperms provided evidence for involvement of both the DBEs in rice endosperm amylopectin biosynthesis (Fujita et al. 2003; Kubo et al., 1999; Nakamura, 1996; Wong et al., 2003).

\section{Challenges and future prospects}

Most of the economically important traits in crop plants have been genetically manipulated to improve cultivars with extreme level of phenotype such as high resistance, high protein and oil content. But in the case of improving rice grain quality, majority of the consumers in the world prefer the rice with intermediate AC and GT because of the good cooking and eating qualities. Considering the array of grain quality features either directly or indirectly affected by complex network of SS enzymes, the improvement is more cumbersome and difficult using conventional breeding approaches alone. Since the very beginning, plant breeders working on the improvement of the rice grain quality have always targeted AC and GT as a measure to assess the physicochemical/starch properties traits in the rice for selecting improved lines with desirable range of AC and GT. On the other hand, biochemists improved our understanding on roles of the starch-synthesizing enzymes in the synthesis of amylose and amylopectin, which has helped in understanding the starch biosynthesis in rice endosperm in a better way. In addition, genomic regions responsible for the cooking quality traits were identified through forward genetics approach by mapping the QTLs and genes. Using advanced genomic approaches, recent studies reported identification of starch-synthesizing genes and their isoforms by reverse genetics approach and attempted to relate their effects on rice grain quality traits. Majority of the reports clearly identified chromosome 6 to be rich in the genes related to starch properties (GBSS-I, SSIIa and $S B E-1)$ along with other genomic regions scattered in rice genome and, hence, a holistic approach is required by pooling the information generated through forward genetics (QTLs/genes for AC and GT) and reverse genetics (genes responsible for different starch-synthesizing enzymes) approach to utilize the information for improving these traits. The genomic regions responsible for the starch properties traits (AC, GT) and starch-synthesizing enzymes (SS, SBEs, DBEs) need to be compared and perfect molecular markers should be developed, which can explain the variation for starch-synthesizing enzymes and starch properties traits together. Since the full genome sequence information is available in the public domain for an Indica genotype (BG-1) and a Japonica genotype (Nipponbare) along with large number of EST database, these databases should be used judiciously to develop tightly linked markers. Although it looks difficult to develop perfect markers for each isoforms of all the enzymes involved in starch synthesis in rice endosperm controlling desirable range of AC and GT, if done so, it will definitely help the breeders to develop rice variety with desirable cooking and eating quality with more precision using the maker-assisted selection.

\section{Acknowledgements}

The authors thank Dr. Kanwar L. Sahrawat, Adjunct Scientist, RP-Dry Land Cereals, International Crops Research Institute for Semi-Arid Tropics (ICRISAT), Hyderabad, India, for critically reviewing this manuscript. 


\section{References}

Akagi H, Yokozeki Y, Inagaki A, Fujimura T. Microsatellite DNA marker for rice chromosomes. Theor Appl Genet 1996;93:1071-7.

Aluko G, Maetinez C, Tohme J, Castano C, Bergman C, Oard JH. QTL mapping of grain quality traits from inter-specific cross Oryza sativa $\times 0$. glaberrima. Theor Appl Genet 2004;109:630-9.

Amaravathi Y, Singh R, Singh AK, Singh VP, Mohapatra T, Sharma TR, et al. Mapping of quantitative trait loci for basmati quality traits in rice. Mol Breed 2008;21:49-65.

Asaoka M, Okuno K, Yano M, Fuwa H. Effects of shrunken and other mutations on the properties of rice endosperm starch. Starch/Starke 1993;45:383-7.

Ayres NM, McClung AM, Larkin PD, Bligh HFJ, Jones CA, Park WD. Microsatellites and single nucleotide polymorphism differentiate apparent amylose classes in an extended pedigree of US rice germplasm. Theor Appl Genet 1997;94:773-81.

Bao JS, Sun M, Corke M. Analysis of genetic behavior of some starch properties in Indica rice (Oryza sativa L): thermal properties, gel texture, swelling value. Theor App Genet 2002;104:408-13.

Bao JS, Sun M, Zhu LH, Corke H. Analysis of quantitative trait locus for same starch properties in rice thermal properties, gel texture, swelling volume. J Cereal Sc 2004;39:379-85

Bao JS, Corke H, Sun M. Nucleotide diversity in starch synthase Ila and variability of single nucleotide polymorphisms in relation to starch gelatinization temperature and other physicochemical properties in rice. Theor Appl Genet 2006;113. http: //dx.doi.org/10.1007/S/00122-006-0355-6.

Bergman CJ, Delgado JT, Fjellstron RG, McClung AM. Evaluation of breeding lines using a rapid method for microsatellite associated with waxy gene. Texas Rice Research and Education Programme. Bottom Lime Report. Texas A \& M University; 2000.

Blauth SL, Yao Y, Klucinec JD, Shannon JC, Thompson DB, Guiltinan M. Identification of Mutator insertional mutants of starch-branching enzyme $2 a$ in corn. Plant Physiol 2001:125:1396-405.

Blauth SL, Kim KN, Klucinec J, Shannon JC, Thompson DB, Guiltinan M. Identification of Mutator insertional mutants of starch-branching enzyme 1 (sbe1) in Zea mays L. Plant Mol Biol 2002:48:287-97.

Bligh HFJ, Til RI, Jones CA. A microsatellite sequence closely linked to the waxy gene of Oryza sativa. Euphytica 1995;86:83-5.

Bollich CN, Webb BD. Inheritance of amylose in two hybrid populations of rice. Cerea Chem 1973:50:631-7.

Butardo VM, Fitzgerald MA, Bird AR, Gidley MJ, Flanagan BM, Larroque O, et al. Impact of down-regulation of starch branching enzyme IIb in rice by artificial microRNAand hairpin RNA-mediated RNA silencing. J Exp Bot 2011;62:4927-41.

Cai XL, Wang ZY, Xing YY, Zhang JL, Hong MM. Abberant splicing of intron 1 leads to the heterogenous 5' UTR and decreased expression of waxy gene in rice cultivars of intermediate amylose content. Plant J 1998;14:459-65.

Chang WL, Li WY. Inheritance of amylose content and gel consistency in rice. Bot Bull Acad Sin 1981;22:35-47.

Chauhan JS, Nanda JS. Inheritance of amylose content and its association with grain yield and yield contributing characters in rice. Oryza 1983;20:81-5.

Chen MH, Huang LF, Li HM, Chen YR, Yu SM. Signal peptide-dependent targeting of a rice $\alpha$-amylase and cargo proteins to plastids and extracellular compartments of plant cells. Plant Physiol 2004;135:1367-77.

Chen M, Bergman CJ, Pinson SR, Fjellstrom RG. Waxy gene haplotypes: associations with pasting properties in an international rice germplasm collection. J Cereal Sci 2008;48:781-8.

Delrue B, Fontaine T, Routier F, Decq A, Wieruszeski JM, Ball S. Waxy Chlamydomonas reinhardtii: monocellular algal mutants defective in amylose biosynthesis and granule-bound starch synthase activity accumulate a structurally modified amylopectin Bacteriol 1992;174:3612-20.

Denyer K, Dunlop F, Thorbornsen T, Keeling P, Smith AM. The major form of ADP-glucose pyrophosphorylase in maize endosperm is extra-plastidial. Plant Physiol 1996;112: 779-85.

Fan CC, Yu XQ, Xing YZ, Yu CG, Luo LJ, Zhang QF. The main effects, epistatic effects and environmental interactions of QTLs on the cooking and eating quality of rice in doubled haploid line population. Theor Appl Genet 2005;110:1445-52.

Fitzgerald MA. Starch. In: Champagne ET, editor. Rice chemistry and technology. St Paul, MN: AACC; 2004.

Flipse E, Suurs L, Keetels CJA, Kossmann J, Jacobsen E, Visser RGF. Introduction of sense and antisense cDNA for branching enzyme in the amylose-free potato mutan leads to physico-chemical changes in the starch. Planta 1996;198:340-7.

Fu FF, Xue HW. Coexpression analysis identified rice starch regulator 1a Rice AP2/EREBP family transcription factor, as a novel rice starch biosynthesis regulator ${ }^{1[\mathrm{w}][\mathrm{OA}]}$. Plant Physiol 2010;154:927-38.

Fujita N, Taira T. A 56-kDa protein is a novel granule-bound starch synthase existing in the pericarps, aleurone layers, and embryos of immature seed in diploid wheat (Triticum monococcum L.). Planta 1998;207:125-32.

Fujita N, Kubo A, Suh DS, Wong KS, Jane JL, Ozawa K, et al. Antisense inhibition of isoamylase alters the structure of amylopectin and the physicochemical properties of starch in rice endosperm. Plant Cell Physiol 2003;44:607-18.

Fujita N, Yoshida M, Asakura N, Ohdan T, Miyao A, Hirochika H, et al. Function and characterization of starch synthase I using mutants in rice. Plant Physiol 2006;140:1070-84.

Fujita N, Yoshida M, Kondo T, Saito K, Utsumi Y, Tokunaga T, et al. Characterization of SSIIIa-defficient mutants of rice: the function of SSIIIa and pleiotropic effects by SSIIIa defficieny in the rice endosperm. Plant Physiol 2007;144:2009-23.

Gao ZY, Zheng DL, Cui X, Zhou YH, Yan M, Huang D, et al. Map based cloning of the ALK gene, which controls GT of rice. Sci China C Life Sci 2003;46:661-8.

Ghosh AK, Govindswamy S. Inheritance of starch iodine blue value and alkali digestion value in rice and their genetic association. II Riso 1997;21:123-32.
Govindraj P, Vinod KK, Arumugachamy S, Maheswaran M. Analyzing genetic control of cooked grain traits and gelatinization temperature in a double haploid population of rice by quantitative trait loci mapping. Euphytica 2009;166:165-76.

Guan HP, Preiss J. Differentiation of the properties of the branching isoenzymes from maize (Zea mays). Plant Physiol 1993;102:1269-73.

Han Y, Xu M, Liu X, Yan C, Korban SS, Chen X, et al. Genes coding for starch branching enzymes are major contributors to starch viscosity characteristics in waxy rice. Plant Sci 2004;166:357-64.

He P, Li SG, Xian Q Ma YQ, Li JZ, Wang WM, et al. Genetic analysis of rice grain quality. Theor Appl Genet 1999;95:502-8.

He Y, Han Y, Lu J, Xu C, Lu J, Xu M. Functional analysis of starch synthesis genes in determining rice eating and cooking qualities. Mol Breed 2006;18:277-90.

Heda GD, Reddy GM. Studies on the inheritance of amylose content and gelatinization temperature in rice. Genet Agric 1986;40:1-8.

Heu MH, Choi ZR. Inheritance of alkali digestibility of rice grain in the Indica Japonica crosses. Korean J Breed 1973;5:32-6.

Heu MH, Park SZ. Dosage effect of waxy alleles on amylose content of rice grain. I. Amylose of hybrid seeds obtained from male sterile stocks. Seoul Natl Univ Coll Agric Bull 1976;1:39-46.

Hirose T, Terao T. A comprehensive expression analysis of starch synthase gene family in rice (Oryza sativa L.). Planta 2004;220:9-16

Hsieh SC, Wang LH. Genetical studies on grain quality in rice. In: Song S, Hong MC, editors. Proc. Symp. On Rice Grain Quality; 1988. p. 117-36.

Imparl-Radosevich JM, Gameon JR, McKean A, Wetterberg D, Keeling P, Guan H. Understanding catalytic properties and functions of maize starch synthase isozymes. J Appl Glycosci 2003:50:77-182.

Isshiki M, Nakajima M, Satoh H, Shimamoto K. Dull: rice mutants with tissue specific affects on the splicing of the waxy pre mRNA. Plant J 2000;23:451-60.

James MG, Denyer K, Myres AM. Starch synthesis in the cereal endosperm. Curr Opin Plant Biol 2003;6:215-22.

Jeon J-S, Ryoo N, Hahn T-R, Walia H, Nakamura Y. Starch biosynthesis in cereal endosperm. Plant Physiol Biochem 2010;48:383-92.

Juliano BO, Bautista GM, Lugay JC, Reyes AC. Studies on physicochemical properties in rice. J Agric Food Chem 1964;12:31-8.

Juliano BO, Perez CM, Blakeney AB, Castillo DT, Kongseree N, Laignelet B, et al. International co-operative testing on the amylase content of milled rice. Starch/Starke 1981;33: 157-62.

Kahlon PS. Inheritance of alkali digestion index and iodine value in rice. Diss Abstr $1965 ; 25: 512$

Kaw RN, Cruz NM. Interrelations among physicochemical grain quality characters in rice. J Genet Breed 1990;44:139-41.

Keeling PL, Myres AM. Biochemistry and genetics of starch synthesis. Annu Rev Food Sci Technol 2010;1:271-303.

Kubo A, Fujita N, Harada K, Matsuda T, Satoh H, Nakamura Y. The starch-debranching enzymes isoamylase and pullulanase are both involved in amylopectin biosynthesis in rice endosperm. Plant Physiol 1999;121:399-409.

Kumar I, Khush GS. Genetics of amylose content in rice. J Genet 1986:65:1-11.

Kuriki T, Stewart DC, Preiss J. Construction of chimeric enzymes out of maize endosperm branching enzymes I and II: activity and properties. J Biol Chem 1997;272: 28999-9004.

Lanceras JC, Huang ZL, Naivikul O, Vanavichit A, Ruanjaichon V, Tragoonrung S. Mapping of genes for cooking and eating qualities in Thai jasmine rice (KDML 105). DNA Res 2000; 7:93-101.

Larkin PD, Park WD. Association of waxy gene single nucleotide polymorphism with starch characteristics in rice. Mol Breed 2003;12:335-9.

Lee SK, Hwang SK, Han M, Eom JS, Kang HG, Han Y, et al. Identification of the ADP-glucose pyrophosphorylase isoforms essential for starch synthesis in the leaf and seed endosperm of rice. Plant Mol Biol 2007:65:531-46.

Li Z, Wan J, Xia J, Yano M. Mapping of quantitative trait loci controlling physicochemical properties of rice grains (Oryza sativa). Breed Sci 2003:53:209-15.

Liu Q, Li QF, Cai XL, Wang HM, Tang SZ, Yu HX, et al. Molecular marker-assisted selection for improved cooking and eating quality of two elite parents of hybrid rice. Crop Sci 2006;46:2354-60.

Maddelein ML, Libessart N, Bellanger F, Delrue B, D'Hulst C, Ball S. Toward an understanding of the biogenesis of the starch granule: determination of granule-bound and soluble starch synthase functions in amylopectin synthesis. J Biol Chem 1994;269:25150-7.

McKenzie KS, Rutger JM. Genetic analysis of amylose content, alkali spreading score and grain dimensions in rice. Crop Sci 1983;23:306-11.

Mikami I, Aikawa M, Hirano HY, Sano Y. Altered tissue specific expression at the $W x$ gene of the opaque mutants in rice. Euphytica 1999;105:91-7.

Mikami I, Uwatoko N, Ikeda Y, Yamaguchi J, Hirano HY, Suzuki Y, et al. Allelic diversification at the Wx locus in landraces of Asian rice. Theor Appl Genet 2008;116: 979-89.

Morrison WR, Karkalas J. Starch. In: dey PM, editor. Methods in Plant Biochemistry, Carbohydrates, 2. ; 1990. p. 323-52.

Myers AM, Morell MK, James MG, Ball SG. Recent progress toward understanding the biosynthesis of the amylopectin crystal. Plant Physiol 2000;122:989-98.

Nakamura Y. Some properties of starch debranching enzymes and their possible role in amylopectin biosynthesis. Plant Sci 1996;121:1-18.

Nakamura Y. Towards a better understanding of the metabolic system for amylopectin biosynthesis in plants: rice endosperm as a model tissue. Plant Cell Physiol 2002;43:718-25.

Nakamura Y, Sakurai A, Inaba Y, Kimura K, Iwasaea N, Nagamine T. The fine structure of amylopectin in endosperm from Asian cultivated rice can be largely classified into two classes. Starch 2002:54:117-31. 
Nakamura Y, Francisco Jr PB, Hosoka Y, Satoh A, Sawada T, Kubo A, et al. Essential amino acids of starch synthase Ila differentiate amylopectin structure and starch quality between Japonica and Indica rice varieties. Plant Mol Biol 2005;58:213-27.

Nakamura Y, Utsumi Y, Sawada T, Aihara S, Utsumi C, Yoshida M, et al. Characterizations of the reactions of starch branching enzymes from rice endosperm. Plant Cell Physiol 2010;51:776-94

Nishi A, Nakamura Y, Tanaka N, Satoh H. Biochemical and genetic effects of amylose-extender mutation in rice endosperm. Plant Physiol 2001:127:459-72.

Noda T, Nishiba Y, Sano T, Suda I. Properties of starches from several low amylose rice cultivars. Cereal Chem 2003;80:193-7.

Ohdan T, Francisco Jr PB, Sawada T, Hirose T, Terao T, Satoh H, et al. Expression profiling of genes involved in starch synthesis in sink and source organs of rice. J Exp Bot 2005;56:3229-44.

Okuno K. Gene dosage effect of waxy alleles on amylose content in endosperm starch of rice. Jpn J Genet 1978;53:219-22.

Okuno K, Yano M. New endosperm mutants modifying starch characteristics of rice (Oryza sativa L.)'. Jpn Agric Res 1984;18:73-84.

Olsen KM, Purugganan MD. Molecular evidence on the origin and evaluation of glutinous rice. Genetics 2002;162:941-50.

Preiss J, Sivak M. Starch synthesis in sinks and sources. In: Zamski E, Schaffter AA, editors. Photoassimilate distribution in plants and crops: sink-source relationships. New York: Marcel Dekker; 1996. p. 63-96.

Puri RP, Siddiq EA. Inheritance of gelatinization temperature in rice. Indian J Genet Plant Breed 1980;40:4610-20.

Rahman S, Regina A, Li Z, Mukai Y, Yamamoto M, Kosar-Hashemi B, et al. Comparison of starch-branching enzyme genes reveals evolutionary relationships among isoforms. Characterization of a gene for starch-branching enzyme Ila from wheat D genome donor Aegilops tauschii. Plant Physiol 2001;125:1314-24.

Sano Y. Differential regulation of waxy gene expression in rice endosperm. Theor Appl Genet 1984;68:467-73.

Satoh H, Nishi A, Fujita N, Kubo A, Nakamura Y, Kawasaki T, et al. Isolation and characterization of starch mutantsin rice. J Appl Glycosci 2003a;50:225-30.

Satoh H, Nishi A, Yamashita K, Takemoto Y, Tanaka Y, Hosaka Y, et al. Starch-branching enzyme I-deficient mutation specifically affects the structure and properties of starch in rice endosperm. Plant Physiol 2003b;133:1111-21.

Seetharaman R. The inheritance of iodine value in rice and its association with other characters. Diss Abstr 1959;20:856.

Septiningsih EM, Trijatiniko KR, Moeljopawiro S, McCouch SR. Identification of quantitative loci for grain quality in an advanced backcross population derived from the Oryza sativa variety IR 64 and the wild relative O. rufipogon. Theor Appl Genet 2003;107:1433-41.

Shobha Rani N, Pandey MK, Prasad GSV, Sudharshan I. Historical significance, grain quality features and precision breeding for improvement of export quality basmati varieties in India. Indian J Crop Sci 2006;1:29-41.

Shobha Rani N, Madhav MS, Pandey MK, Sundaram RM, Prasad GSV, Sudharshan I, et al. Genetics and molecular approaches for improvement of grain quality traits in rice. Indian J Crop Sci 2008;3:1-14.

Shobha Rani N, Pandey MK, Subba Rao LV, Sudharshan I, Ramprasad AS, GSV Prasad. Grain quality variation among physical, chemical and cooking properties in Indian rices. 2011a; (Unpublished).

Shobha Rani N, Sivaranjini AKP, Madhav MS, Sundaram RM, Prasad GSV, Sreekanth S, et al. Identification of molecular markers linked to quality parameters in rice, their validation and utilization in marker-assisted selection. Indian J Genet Plant Breed 2011b;71: 129-38.

Smith AM, Denyer K, Martin C. The synthesis of the starch granule. Annu Rev Plant Physiol Plant Mol Biol 1974;8:67-87.

Somrith B. Genetic analysis of traits related to grain yield and quality in two crosses of rice. Ph.D. thesis, IARI, New Delhi; 1974

Stansel JW. The influence of heredity and environment on endosperm characteristics of rice'. Diss Abstr 1966;27:48B.

Sun S, Hao W, Lin H. Identification of QTLs for cooking and eating quality of rice grain. Rice Sci 2006;13:161-9.

Takeda Y, Hizukari S, Juliano BO. Structures of rice amylopectins with low and high affinities for iodine. Carbohydr Res 1987;168:79-88.
Takeda Y, Tomooka S, Hizukari S. Structures of branched and linear molecules of rice amylose. Carbohydr Res 1993;46:267-72.

Tan YF, Zhang QF. Correlation of simple sequence repeats (SSR) variants in the leader sequence of waxy gene with amylase content of the grain in rice. Acta Bot Sin 2001;43:146-50.

Tan YF, Li JX, Yu SB, Xing YZ, Xu CG. The three important traits for cooking and eating quality of rice grains are controlled by a single locus in an elite rice hybrid, Shanyou 63. Theor Appl Genet 1999:99:642-8.

Tanaka N, Fujita N, Nishi A, Satoh H, Hosaka Y, Ugaki M, et al. The structure of starch can be manipulated by changing the expression levels of starch branching enzyme IIb in rice endosperm. Plant Biotechnol J 2004;2:507-16.

Tang SX, Khush GS, Juliano BO. Variation and correlation of four cooking and eating indices of rices. Phillipp J Crop Sci 1989;14:45-9.

Tetlow IJ. Understanding storage starch biosynthesis in plants: a means to quality improvement. Can J Bot 2006;84:1167-85.

Tetlow IJ, Morell MK, Emes MJ. Recent developments in understanding the regulation of starch metabolism in higher plants. J Exp Bot 2004;55:2131-45.

Tian R, Jiang JH, Shen LH, Wang LQ, He YQ. Mapping quantitative trait loci underlying the cooking and eating quality of rice using a DH population. Mol Breed 2005;15: 117-24.

Tian Z, Quian Q Liu Q Yan M, Liu X, Yan C, et al. Allelic diversities in rice starch biosynthesis lead to a diverse array of rice eating and cooking qualities. Proc Natl Acad Sci U S A 2010;106:21760-5.

Tomar JB, Nanda JS. Genetics and association studies of kernel shape in rice. Indian J Genet $1985 ; 45: 278-83$

Umemoto T, Yano M, Satoh H, Shomura A, Nakamura Y. Mapping of a gene responsible for the difference in amylopectin structure between japonica-type and indica-type rice varieties. Theor Appl Genet 2002;104:1-8.

Utsumi Y, Utsumi C, Sawada T, Fujita N, Nakamura Y. Functional diversity of isoamylose oligomers: the ISA1 homo-oligomer is essential for amylopectin biosynthesis in rice endosperm $^{1[\mathrm{~W}][\mathrm{OA}]}$. Plant Physiol 2011;156:61-77.

van de Wal M, d'Hulst C, Vincken JP, Buleon A, Visser R, Ball S. Amylose is synthesized in vitro by extension of and cleavage from amylopectin. J Biol Chem 1998;273: 22232-40.

Vandeputte GE, Decour JA. From sucrose to starch granule to starch physical behaviour: a focus on rice starch. Carbohydr Polym 2004;58:245-66.

Vrinten P, Nakamura T. Wheat granule-bound starch synthase I and II are encoded by separate genes that are expressed in different tissues. Plant Physiol 2000;122: 255-63.

Wan XY, Wan JM, Su CC, Wang CM, Shen WB, Li JM, et al. QTL detection for eating quality of cooked rice in a population of chromosome segment substitution lines. Theor Appl Genet 2004;110:71-9.

Wang ZY, Zheng FQ, Shen GZ, Gao JP, Sunstad DP, Li MG, et al. The amylose content in rice endosperm is revealed to the post-transcriptional regulation of the waxy gene. Plant J 1995; 7:613-22.

Wang LQ Liu WJ, Xu Y, He YQ Luo LJ, Xing YZ, et al. Genetic basis of 17 traits and viscosity parameters characterizing the eating quality of rice grain. Theor Appl Genet 2007;115: 463-76.

Wong KS, Kubo A, Jane JL, Harada K, Satoh H, Nakamura Y. Structures and properties of arnylopectin and phytoglycogen in the endosperm of sugary-1 mutants of rice. J Cereal Sci 2003;37:139-49.

Yano M, Okuno K, Satoh H, Omura T. Chromosomal location of gene conditioning low amylose content of endosperm starches in rice, Oryza sativa L. Theor Appl Genet 1988;76:183-9.

Yu G, Olsen KM, Schaal BA. Association between nonsynonymous mutations of starch synthase IIa and starch quality in rice (O. sativa). New Phytol 2011;189:593-601.

Zhang G, Cheng Z, Zhang X, Guo X, Su N, Jiang L, et al. Double repression of soluble starch synthase genes SSIIa and SSIIIa in rice ( $O$. sativa $\mathrm{L}$.) uncovers interactive effects on physic-chemical properties of starch. Genome 2011;54:448-59.

Zheng X, Wu JG, Lou XY, Xu HM, Shi CH. The QTL analysis on maternal and endosperm genome and their environmental interactions for characters of cooking quality in rice. Theor Appl Genet 2008;116:335-42. 